Synovial chondromatosis of the temporomandibular joint : condyle osteotomy of the mandible and patient-specific fixation implant

\title{
Haapalainen, L.
}

2020-11

Haapalainen , L \& Snäll , J 2020 , ' Synovial chondromatosis of the temporomandibular joint : condyle osteotomy of the mandible and patient-specific fixation implant ', British Journal of Oral and Maxillofacial Surgery, vol. 58 , no. 9 , pp. E122-E123 . https://doi.org/10.1016/j.bjoms.2020.06.016

http://hdl.handle.net/10138/340111

https://doi.org/10.1016/j.bjoms.2020.06.016

cc_by_nc_nd

acceptedVersion

Downloaded from Helda, University of Helsinki institutional repository.

This is an electronic reprint of the original article.

This reprint may differ from the original in pagination and typographic detail.

Please cite the original version. 


\begin{tabular}{|c|c|}
\hline \multicolumn{2}{|c|}{$\begin{array}{l}\text { British Journal of Oral \& Maxillofacial Surgery } \\
\text { CHONDROMATOSIS OF THE TEMPOROMANDIBULAR JOINT: } \\
\text { TEOTOMY OF THE MANDIBLE AND PATIENT-SPECIFIC FIXATION } \\
\text { IMPLANT } \\
\text {--Manuscript Draft-- }\end{array}$} \\
\hline \multicolumn{2}{|l|}{ Manuscript Number: } \\
\hline Article Type: & Technical Note \\
\hline Keywords: & synovial chondromatosis, temporomandibular joint, patient specific implant \\
\hline Corresponding Author: & $\begin{array}{l}\text { Leena Haapalainen, DDS } \\
\text { Helsinki University } \\
\text { Helsinki, Finland FINLAND }\end{array}$ \\
\hline First Author: & Anna-Leena Elisabet Haapalainen, DDS \\
\hline \multirow[t]{2}{*}{ Order of Authors: } & Anna-Leena Elisabet Haapalainen, DDS \\
\hline & Johanna Snäll, MD, DDS, PhD \\
\hline Manuscript Region of Origin: & FINLAND \\
\hline
\end{tabular}


Title page - List of all author names, their contact details and affiliations and indicating corresponding author

SYNOVIAL CHONDROMATOSIS OF THE TEMPOROMANDIBULAR JOINT: CONDYLE OSTEOTOMY OF THE MANDIBLE AND PATIENT-SPECIFIC FIXATION IMPLANT

Haapalainen, Leena, DDS ${ }^{1}$

Snäll, Johanna, MD, DDS, $\mathrm{PhD}^{1}$

${ }^{1}$ Department of Oral and Maxillofacial Diseases, University of Helsinki and Helsinki University Hospital, Helsinki, Finland

\section{CORRESPONDING AUTHOR}

Leena Haapalainen, Department of Oral and Maxillofacial Diseases, University of Helsinki and Helsinki University Hospital, FI-00029 HUH, Finland

E-mail: leena.haapalainen@gmail.com 


\section{SYNOVIAL CHONDROMATOSIS OF THE TEMPOROMANDIBULAR JOINT: CONDYLE OSTEOTOMY OF THE MANDIBLE AND PATIENT-SPECIFIC FIXATION IMPLANT}

Synovial chondromatosis (SC) of the temporomandibular joint is a rare benign pathologic condition in which cartilaginous nodules form in the synovial lining. ${ }^{2}$ The etiology for the primary SC is unknown, but has been suggested to follow trauma, embryological disturbances, or infection. ${ }^{1,3}$ Symptoms include pain in the TMJ (temporomandibular joint), limited mouth opening, swelling, occlusion changes, and deviation. ${ }^{3}$ CT (computer tomography) and MRI (magnetic resonance imaging) are leading diagnostic imaging methods. ${ }^{4}$ The final diagnosis is confirmed by pathological examination. The SC treatment is surgery to remove the loose bodies. Arthrotomy with synovectomy is the most common reported treatment. ${ }^{2}$ These are sometimes accompanied by articular disc resection and condylar resection. ${ }^{5}$ The extension and location of the disease affect the choice of the surgical approach. The surgery should aim to eliminate any remaining lesion in the middle cranial fossa and in the infratemporal fossa, ${ }^{2}$ which can lead to extensive surgery. A good alternative may be a condyle osteotomy. ${ }^{5} \mathrm{We}$ present a case of synovial chondromatosis successfully treated with joint-conserving surgery with an osteotomy of the condyle and a repositioning of the condyle with a patient-specific implant.

A healthy 49-year-old male presented for evaluation with pain and swelling in the right preauricular region and restricted mouth opening. The patient had a history of blunt condylar trauma 20 years earlier. MRI revealed a pathological expansion of the synovial capsule, erosion of the cranial base and glenoid fossa, and an abundant mass of calcified bodies surrounding the condyle. Access to the lesion was particularly challenging considering that the majority of the nodules were situated on the medial aspect of the condyle. Preoperative planning and surgery were performed at the Department of Oral and Maxillofacial Surgery, Helsinki University Hospital, Finland. A patient-specific titanium implant was designed and engineered with the Planmeca ProModel ${ }^{\mathrm{TM}}$ system (Planmeca Ltd), and screw directions were optimized along the thickest bone area of the condyle. The osteotomy line was preplanned virtually. The lesion was exposed via preauricular approach and the condyle osteotomy via retromandibular approach. Screw holes for the patient-specific implant were predrilled, and the implant was temporarily fixed on the planned osteotomy line on the neck of the condyle. A low osteotomy was performed according to the planned line based on the implant position. 
The right condyle was turned on the side inferiorly to achieve proper coverage on the surgical field. The lesion was curetted on visual contact. The condyle was repositioned, and the implant was fixed with bicortical screws. Diagnosis of synovial chondromatosis was histopathologically confirmed. The postoperative course was uncomplicated.

The middle cranial fossa has traditionally been accessed via coronal approach, and the zygomatic arch has usually been osteotomized. A low condyle osteotomy is a technique worth consideration in benign conditions to achieve an excellent view of the lesion extending to the fossa, preserving the function of the TMJ and simultaneously generating only moderate morbidity. Using a patient-specific implant in the fixation of the osteotomy line ensures the optimal position of the fixation screws and the precise repositioning of the condyle. 
Figure legend to Fig. 1

A 49-year old male had restricted mouth opening, swelling, and pain on the right mandibular condyle. MRI showed pathological expansion of the synovial capsule and glenoid fossa and an abundant mass of calcified bodies surrounding the condyle. Synovial chondromatosis was suspected according to the radiological imaging.

Figure legend to Fig 2.

The osteotomy line was fixed, and the mandibular condyle was repositioned with a patientspecific implant. A postoperative dental panoramatomography image showed the exact position of the right condyle. 


\section{REFERENCES}

1. Holmlund AB, Eriksson L, Reinholt FP. Synovial chondromatosis of the temporomandibular joint: clinical, surgical and histological aspects. Int J Oral Maxillofac Surg. 2003;32(2):143-7

2. Xu WH, Ma XC, Guo CB, et al. Synovial chondromatosis of the temporomandibular joint with middle cranial fossa extension. Int J Oral Maxillofac Surg. 2007;36(7):652-5.

3. Ardekian L, Faquin W, Troulis MJ, et al. Synovial chondromatosis of the temporomandibular joint: report and analysis of eleven cases. J Oral Maxillofac Surg. 2005;63(7):941-7.

4. Benslama L, Schouman T, Toure S, et al. Synovial chondromatosis of the temporomandibular joint: Report and analysis of 12 cases. J Stomatol Oral Maxillofac Surg. 2019;120(5);476-479.

5. Nath, P. Menon, S. Synovial Chondromatosis of the Temporomandibular Joint. J. Maxillofac Oral Surg. (2019). https://doi-org.libproxy.helsinki.fi/10.1007/s12663-019-01194-0 


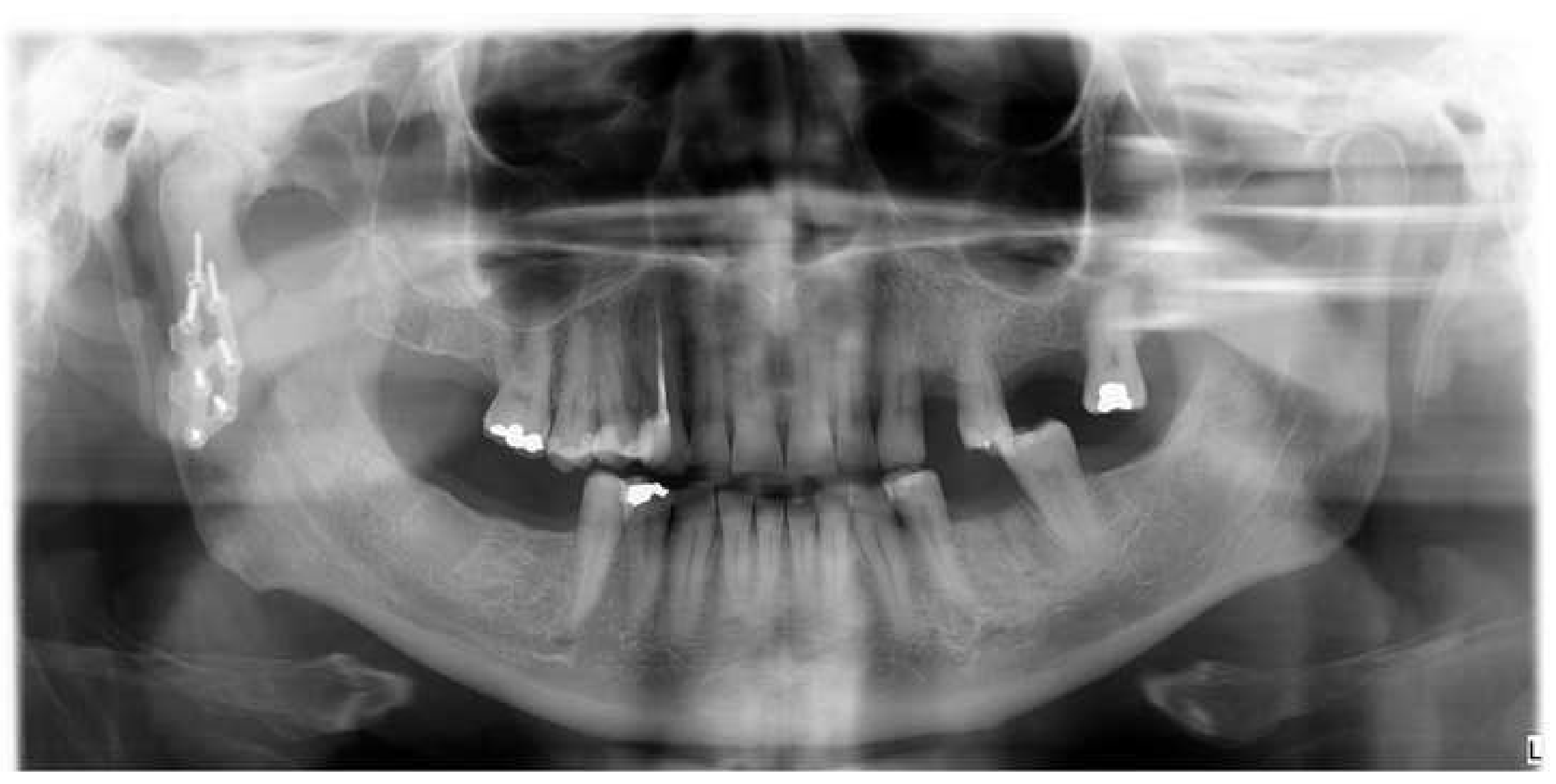

\section{.}

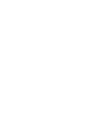




\section{BRITISH JOURNAL OF ORAL \& MAXILLOFACIAL SURGERY}

\section{Author contribution}

Manuscript Title SYNOVIAL CHONDROMATOSIS OF THE TEMPOROMANDIBULAR JOINT: CONDYLE OSTEOTOMY OF THE MANDIBLE AND PATIENT-SPECIFIC FIXATION IMPLANT

Please provide details in the table below of each author(s) contribution to the submitted manuscript

\begin{tabular}{|l|l|l|l|l|l|}
\hline \multicolumn{1}{|c|}{ AUTHORS } & $\begin{array}{l}\text { Conception and } \\
\text { design of } \\
\text { study/review/case } \\
\text { series }\end{array}$ & $\begin{array}{l}\text { Acquisition of } \\
\text { data: laboratory } \\
\text { or } \\
\text { clinical/literature } \\
\text { search }\end{array}$ & $\begin{array}{l}\text { Analysis and } \\
\text { interpretation } \\
\text { of data } \\
\text { collected }\end{array}$ & $\begin{array}{l}\text { Drafting of } \\
\text { article and/or } \\
\text { critical } \\
\text { revision }\end{array}$ & $\begin{array}{l}\text { Final approval } \\
\text { and guarantor } \\
\text { of manuscript }\end{array}$ \\
\hline Snäll, Johanna & $\mathbf{X}$ & $\mathbf{x}$ & $\mathbf{x}$ & $\mathbf{x}$ & $\mathbf{x}$ \\
\hline Haapalainen, Leena & $\mathbf{x}$ & $\mathbf{x}$ & $\mathbf{x}$ & & \\
\hline & & & & & \\
\hline & & & & & \\
\hline
\end{tabular}




\begin{tabular}{|l|l|l|l|l|}
\hline & & & & \\
\hline
\end{tabular}




\title{
The British Journal of Oral \& Maxillofacial Surgery CONFIRMATION OF AUTHORSHIP
}

\begin{abstract}
TITLE: SYNOVIAL CHONDROMATOSIS OF THE TEMPOROMANDIBULAR JOINT: CONDYLE OSTEOTOMY OF THE MANDIBLE AND PATIENT-SPECIFIC FIXATION IMPLANT
\end{abstract}

REFERENCE NO:

We, the undersigned, confirm that we are the joint authors of the above paper.

We confirm that all the authors have had material input into the submission.

We confirm that, to our knowledge, all the claims, statements and conclusions are true and are our jointly held opinions.

We confirm that we all accept the terms of publication of the publisher.

Signed:

Name: ....ohanna Snnäll!

Signature:

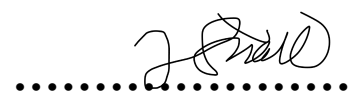

Name: ... Leena Haapala...........n

Signature: ....ena...........................

Name:

Signature:

Name:

Signature:

Name:

Signature:

Name:

Signature:

This form must be signed by all the authors of the above paper and the original scanned and emailed to the journal office (BJOMS@elsevier.com) or uploaded with the PDF of the manuscript.

Original signatures and required and photocopies are not acceptable. If your paper is accepted, publication will not proceed until the fully completed form is received. 
Leena Haapalainen

Department of Oral and Maxillofacial Diseases, University of Helsinki and Helsinki University Hospital, FI-00029 HUS, Finland

Phone: $+358-407084744$

E-mail: leena.haapalainen@gmail.com

Dr. Kaveh Shakib

Editor-in-Chief

British Journal of Oral and Maxillofacial Surgery

Dear Dr. Shakib,

Synovial chondromatosis of the temporomandibular joint with extension to the middle cranial fossa is a rare condition. Only limited amount of literature of its treatment is available at the moment. Depending on the localization and extend of the lesion it can be difficult to operate and extensive surgical approaches are used in order to extract all the cartilaginous nodules from the synovial compartments and cranial fossa. This increases the morbidity of the patient.

We present a technique for surgical access to the middle cranial fossa in case of this benign lesion. Performing a low osteotomy of the condyle and turning the condyle laterally and inferiorly on the side while curetting the lesion is an innovative technique worth of consideration in cases of extent synovial chondromatosis surgical treatment. Using preoperatively planned patient specific implant for the fixation of the condyle osteotomy offers even more value on the technique by allowing precise positioning of the condyle.

Attached is our technical note "Synovial chondromatosis of the temporomandibular joint: condyle osteotomy of the mandible and patient-specific fixation implant" for consideration for publication as a technical note. We believe that this note is appropriate for publication by the British Journal of Oral and Maxillofacial Surgery as it offers valuable new information for the oral- and maxillofacial surgery.

We confirm that this original manuscript has not been published elsewhere and is not under consideration by another journal. The authors have no conflicts of interest to disclose. All authors 
have approved the manuscript and its submission to the British Journal of Oral and Maxillofacial Surgery.

Sincerely,

Leena Haapalainen

DDS

University of Helsinki

Helsinki University Hospital 